\title{
Newly introduced deprivation of liberty safeguards: anomalies and concerns ${ }^{\dagger}$
}

\author{
Ajit Shah, ${ }^{1,2}$ Chris Heginbotham ${ }^{1}$
}

The Psychiatrist (2010), 34, 243-245, doi: 10.1192/pb.bp.109.026831

${ }^{1}$ University of Central Lancashire,

Preston; ${ }^{2}$ West London Mental Health NHS Trust, London

Correspondence to Professor Ajit Shah (ajit.shah@wlmht.nhs.uk)
Summary The European Court of Human Rights found that the care and treatment of $\mathrm{HL}$ in the 'Bournewood case' constituted infringement, in the form of deprivation of liberty, of his rights under Articles 5 (1) and 5 (4) of the European Convention on Human Rights. To prevent the infringement, the Deprivation of Liberty Safeguards were introduced into the Mental Capacity Act 2005 via the Mental Health Act 2007. The recent implementation of the Deprivation of Liberty Safeguards on 1 April 2009 has exposed some anomalies and higlighted some difficulties in its implemention and application, and these are described in the paper.

Declaration of interest Professor Chris Heginbotham was the Chief Executive of the Mental Health Act Commission until 31 March 2008.

\section{Background}

There have been four judicial judgments on the 'Bournewood case' over the last decade: in the High Court, October 1997; the Court of Appeal, December 1997; the House of Lords, June 1998; and the European Court of Human Rights, 2004. A man with autism (HL), with no ability to communicate consent or dissent to hospital admission was admitted informally to the mental health unit of the Bournewood Community and Mental Health NHS Trust following agitated behaviour at a day centre. He was allowed to stay in hospital informally because he made no attempts to leave. In September 1997, the High Court rejected the application for Judicial Review of the hospital's decision to admit him informally, concluding that he had not been detained and he had been admitted lawfully in accordance with the common law doctrine of necessity. An application was made for a Judicial Review to quash the Trust's decision to detain him. The Court of Appeal, on 2 December 1997, concluded that the appellant had been unlawfully detained. ${ }^{1}$ This judgment was subsequently overturned by the House of Lords on 25 June $1998,{ }^{2}$ but this was felt to be based on a legal technicality because it considered whether the patient was 'detained' and if so whether the detention could be justified under the common law doctrine of necessity. ${ }^{3}$ Despite this judgment finding HL to be lawfully detained, Lord Steyn alluded to an ethical and a legal gap for the following reasoning, that 'there can be no justification for not giving to compliant incapacitated patients the same quality and degree of protection as is given to patients admitted under the Act of $1983{ }^{2}{ }^{2}$

The European Court of Human Rights, on 5 October 2004, found that the circumstances surrounding the care

†See editorial pp. 217-220, original paper pp. 221-225 and special article pp. 246-247, this issue. and treatment of HL in the Bournewood Community and Mental Health NHS Trust during a period in which he was not formally detained under the Mental Health Act 1983 constituted infringement, in the form of deprivation of liberty, of his rights under Articles 5(1) and 5(4) of the European Convention on Human Rights. ${ }^{4}$ Article 5(1) was breached because the manner in which HL was deprived of liberty was not in accordance with 'a procedure prescribed by law' (i.e. not under either mental health or other relevant legislation). Article 5(4) was breached because HL was not able to apply to a court to ascertain whether the deprivation of liberty was lawful.

\section{Deprivation of liberty safeguards}

To prevent future breaches of the European Convention on Human Rights or the Human Rights Act 1998, the Mental Capacity Act has been amended via the Mental Health Act 2007 amendments, ${ }^{5}$ to provide safeguards for people who lack capacity, are at least 18 years old, have a mental disorder as defined in the amended Mental Health Act, and whose care or treatment involves deprivation of liberty within the framework of Article 5 of the European Convention on Human Rights, but who are not detained under the Mental Health Act or a court order. These safeguards are referred to as the deprivation of liberty safeguards. Although the European Court of Human Rights judgment on the Bournewood case referred to admission into hospital, the deprivation of liberty safeguards also apply to people living in care homes. These safeguards may apply to those living in care homes because the issues related to deprivation of liberty are similar in both settings, although length of stay, the purpose of admission and inspection processes are different in the two settings. The deprivation of liberty safeguards are supported by a Code of 
Practice. ${ }^{6}$ Six 'qualifying requirements' must be met before such individuals can be deprived of their liberty under the safeguards. These may be considered as the Mental Capacity Act equivalent of the criteria used for detention under the Mental Health Act. The recent implementation of the safeguards on 1 April 2009 has exposed some anomalies and higlighted some difficulties in its implemention and application.

\section{Who does the deprivation of liberty safeguards apply to?}

The deprivation of liberty safeguards applies only to those in hospital or care homes. Individuals living in supported accommodation or in their own homes are excluded. Acutely mentally ill people are increasingly being treated at home by home treatment teams, and many such individuals may be deprived of their liberty. Similarly, many individuals with dementia looked after by family members may also be deprived of their liberty (e.g. people with dementia who are at risk of wandering and getting lost may not be allowed to leave their home by family members). Theoretically, family members involved in such situations could make a formal application to the Court of Protection to ensure that the rights of the individual are protected. However, in practice, this is rarely done because the time and expense involved make this unrealistic.

Deprivation of liberty safeguards only applies to those with a 'mental disorder' as defined in the Mental Health Act, whereas the Mental Capacity Act generally applies to anyone who is incapacitated because of 'an impairment or disturbance of the mind or brain'. It is unclear, therefore, if the safeguards can be applied to individuals lacking capacity to consent to their stay in hospitals or care homes because of neurological disorders such as strokes. A similar argument could be rehearsed for delirium, but the definition of mental disorder in the Mental Health Act, used for deprivation of liberty safeguards purposes, appears to incorporate delirium. Clearly, if the safeguards do not apply in such circumstances then a large number of vulnerable individuals will be denied protection afforded by the safeguards.

Individuals with intellectual disability can only be subject to the provisions of the Mental Health Act if they display abnormally aggressive or seriously irresponsible conduct. However, for the purpose of the deprivation of liberty safeguards these special provisions are disregarded. Thus, those with intellectual disability who do not display abnormally aggressive or seriously irresponsible conduct cannot be detained in hospital under the Mental Health Act, but they could be detained for up to 12 months under the deprivation of liberty safeguards.

\section{Some anomalies and concerns}

Deprivation of liberty is not defined clearly in the relevant legislation and the accompanying Code of Practice. ${ }^{6}$ In the three leading cases, the courts have said that the decisive factor was whether the professionals exercise complete and effective control over the person's care and movements, so that the individual is under their continuous supervision and control and is not free to leave. ${ }^{4,7,8}$ This absence of an agreed legal definition of deprivation of liberty and potential confusion with the less coercive 'restriction' of liberty is already creating difficulties for practitioners in determining what constitutes the threshold for deprivation of liberty, and was highlighted in a study of the Mental Capacity Act prior to the implementation of the deprivation of liberty safeguards. ${ }^{9}$

The statutory provisions under the deprivation of liberty safeguards do not include procedural protection for practitioners and patients similar to that in the Mental Health Act. There is no provision in the safeguards to ensure a power of entry where an individual refuses to be assessed. Moreover, this legislation does not give practitioners statutory powers to convey an individual to the designated care home or hospital, or to return those subject to the safeguards to these settings after having left without agreed leave. Absence of these provisions places practitioners in a difficult position to ensure that individuals potentially eligible for the deprivation of liberty safeguards are assessed for authorisation and those subject to the safeguards are resident in the designated setting.

The government had estimated that 50000 people lacking capacity are being unlawfully deprived of their liberty in care homes. ${ }^{10}$ Assuming that the governmental estimate of 50000 individuals requiring authorisation under the deprivation of liberty safeguards is accurate, two to three times more individuals may need to be assessed to filter out those not requiring authorisation under the safeguards. Another potential problem is that practitioners, managers and proprietors in hospital and care home settings may not be risk averse - in other words, they may use the deprivation of liberty safeguards as a form of insurance against being found in breach of the requirements of the Mental Capacity Act. Thus, many more individuals may be referred for assessment for authorisation under the deprivation of liberty safeguards. More and more anecdotal evidence suggests that local authorities, primary care trusts, care homes and hospitals are not sufficiently organised and resourced to carry out that task.

The expectation was that on 1 April 2009, when the deprivation of liberty safeguards were implemented, all individuals over the age of 18 years with a mental disorder in hospitals and care homes, who lacked the capacity to consent to their stay in those settings and were deprived of their liberty, would be referred for authorisation under the safeguards. Prior to 1 April 2009, such individuals were likely to have been cared for under the Mental Capacity Act in their best interests. Further anecdotal evidence suggests that a significant number of such individuals have failed the eligibility test under the deprivation of liberty safeguards (under this test the assessor determines if the individual should be detained under the Mental Health Act as opposed to the deprivation of liberty safeguards), but have subsequently required assessment for detention under the Mental Health Act, thus possibly increasing the number of individuals detained under the Act. This has also created the additional difficulty of those individuals assessed not to be suitable for detention under the deprivation of liberty safeguards because they fail the eligibility test and are also 
assessed not to fulfil the criteria for detention under the Mental Health Act.

Thus, some individuals who are deprived of their liberty are at potential risk of not being afforded protection under the deprivation of liberty safeguards or the Mental Health Act; the safeguards and the amended Act are not designed in such a manner that one or the other has to be applied as a default position. The Code of Practice for both do not formally address this anomaly, which suggests that the Court of Protection may be required to intervene in such individual cases.

The deprivation of liberty safeguards legislation is not user friendly and is open to a wide range of individual interpretations by those who apply it (Box 1). A new assessment for the deprivation of liberty safeguards must be obtained whenever a person is transferred between care homes or hospitals. For example, elderly people with dementia, who are the highest risk group to require detention under the safeguards and who are at high risk of medical morbidity, may require regular moves between care homes and hospitals. Additionally, the whole process must be repeated at least at yearly intervals, and this may be important in those with dementia because it is a progressive disorder where cognitive impairment increases over time; and the circumstances leading to the original detention under deprivation of liberty safeguards are unlikely to change over time. Moreover, although individuals detained under the safeguards, their representative and their independent mental capacity advocate can apply to their local authority, primary care trust or the Court of Protection for a review of detention under the safeguards, they are not afforded automatic reviews of the type required from the mental health review tribunals for those detained under the Mental Health Act.

Furthermore, although the European Convention on Human Rights requires legal representation and access to a court that can review the lawfulness of the detention, the legal aid scheme for the deprivation of liberty safeguards is minimal. Also, there is no clear provision in the safeguards to cover short periods of deprivation of liberty for individuals needing regular respite care, which is not infrequently used in the clinical management of people with dementia, other than an assessment for authorisation under the safeguards for every respite admission. Institutions that deprive incapacitated persons of their liberty must be subject to supervision by the state, but the Mental Health Act Commission was abolished on the day the deprivation of liberty safeguards were implemented, and the new Care Quality Commission responsible for this task only came into force on the same day. This poor timing may have important implications for the effective and accurate implementation of the safeguards.

\section{Conclusion}

The principles that lie behind the deprivation of liberty safeguards are ambitious and admirable. However, there are a number of problems: several anomalies are likely to exclude vulnerable individuals from the protection afforded by the safeguards; and a range of practical issues related to the direct application of the safeguards may also exclude

\section{Box 1 Summary of concerns}

- Deprivation of liberty safeguards are not user friendly

- Deprivation of liberty safeguards are open to wide interpretation

- New assessment needed every time hospital or care home changes

- Annual assessment needed even for individuals with dementia who have a progressive disorder

- No automatic review of the type afforded in the Mental Health Act

- Legal aid scheme for application to Court of Protection limited

- Does not provide any mechanism for short-term deprivation of liberty such as for respite admissions into hospital or care homes

vulnerable individuals from the protection afforded by it. It is important that those who are involved in the implementation and application of the safeguards are aware of these issues as they may lead to diversion of scarce resources and possible disruption and damage to services. It is likely that many of the issues highlighted in this paper may only be resolved with emerging case law.

\section{About the authors}

Professor Ajit Shah is Professor of Ageing, Ethnicity and Mental Health a the International School for Communities, Rights and Inclusion, University of Central Lancashire, Preston, and also a Consultant Psychiatrist at the West London Mental Health NHS Trust. Professor Chris Heginbotham is Professor of Mental Health Policy and Management at the Institute for Philosophy, Diversity and Mental Health, Centre for Ethnicity and Health, University of Central Lancashire, Preston.

\section{References}

1 Times Law Report. Inability to consent makes detention illegal. The Times 1997; 8 December.

$2 R$ v. Bournewood Community and Mental Health NHS Trust ex part L (1998) 3 WLR 108. House of Lords Judgment, A11ER 319.

3 Eastman N, Peay J. Bournewood: an indefensible gap in mental health law. Capacity is set to become a major clinicolegal issue. BMJ 1998; $\mathbf{3 1 7}$ 94-5

4 HL v. UK (2004) European Court of Human Rights (application no. 45508/99).

5 Department of Health. Mental Health Act 2007. Department of Health 2007 (http://www.opsi.gov.uk/acts/acts2007/pdf/ukpga_20070012_ en.pdf).

6 Ministry of Justice. The Mental Capacity Act 2005. Deprivation of Liberty Safeguards. Code of Practice to supplement the main Mental Capacity Act 2005 Code of Practice. Ministry of Justice, 2008.

7 JE v DE and Surrey County Council (2006) EWHC 3459 (Fam).

8 Storck v Germany (2006) 43 EHRR 96

9 Shah AK, Banner, N, Heginbotham C, Fulford B. The early experience of old age psychiatrists in the application of the Mental Capacity Act 2005: a pilot study. Int Psychogeriatr 2009; 22: 147-57.

10 Department of Health. 'Bournewood Consultation': The Approach to be taken in Response to Judgement of the European Court of Human Rights in the 'Bournewood' case: 4. Department of Health, 2005 (http:// www.dh.gov.uk/prod_consum_dh/groups/dh_digitalassets/@dh/@en/ documents/digitalasset/dh_4108641.pdf). 